\title{
O EXTRANGEIRO NA LÍNGUA MATERNA: (NÃO) DESEJAR AS COISAS ALHEIAS
}

\author{
ViViane Veras ${ }^{*}$
}

\begin{abstract}
Resumo
A relação entre língua materna e língua estrangeira, embora pouco problematizada, é algo que inquieta e desperta curiosidade entre profissionais que mostram sua preocupação com o impacto da língua estrangeira sobre a língua materna; a mistura de línguas; o amor ou aversão das crianças e adolescentes pela língua estrangeira. O lingüista Jean-Claude Milner define língua materna como algo de que a lingüística não dá conta, que excede gramáticas e teorias e pertence ao eixo da poesia, dos lapsos, dos jogos de palavras. Essa língua é materna para certo falante, e podemos dizer, com o autor, que ela materna o falante, fazendo dele um sujeito. Se, como afirma o psicanalista Jean Bergès, somos todos bilíngües, é porque falamos uma língua que tem nela (esquecida) uma outra, uma reserva, uma estrangeiridade, algo que nos é alheio, e que nos faz desejar. Quanto à língua estrangeira, tomada no sentido usual de segunda língua, é preciso levar em conta que sua aprendizagem exige mediaçôes pedagógicas e técnicas, e pode se esgotar em um uso estritamente instrumental (tradução, comunicação, leitura). $\mathrm{O}$ ideal de homogeneidade que marca o cotidiano escolar náo permite que se considere cada criança em sua singularidade, levando em conta seu desejo, e acaba por produzir sintomas (fracasso escolar, problemas no aprendizado, exclusáo). Levantamos a hipótese de que a consideração desse (des)compasso entre as línguas pode permitir uma harmonia, mesmo dissonante, e uma provocação quanto à impossibilidade de obedecer a um mandamento que contraria o desejo.

Palavras-Chave: Língua materna, Língua Estrangeira, singularidade, cotidiano escolar, desejo.
\end{abstract}

\section{The foreign language in the mother tongue: (do not) desire the alien things}

\section{Abstract}

The relation between mother tongue and foreign language, though little questioned, is object of worry and curiosity to professionals who are concerned with the impact of the foreign language on the mother tongue; the mixture of languages; children's and teenagers' love or aversion to the foreign language. The linguist Jean-Claude Milner defines mother tongue as something which linguistics cannot handle, which exceeds grammars and theories and belongs to the poetry field, to lapses, to word play. This language is mother tongue for a certain speaker, and it may be said, with the author, that it mothers the speaker, making him a subject. If, as asserts the psychoanalyst Jean Bergès,

Professora do Unibero e da Unicamp. Doutora em Linguística pela UNICAMP. Email: viveras@uol.com.br. 


\section{Revista Solta a Voz, v. 19, n. 1}

we are all bilinguals, it is because we speak a language which has in itself (forgotten) another one, a reserve, a foreign reserve, something alien to us, which makes us desire. As for the foreign language, in the usual sense as second language, one must take into account the fact that learning it requires pedagogical mediation and techniques and that may end up in a strict use: as a pure instrument (translation, communication, reading). The ideal of homogeneity which characterizes the school routine does not allow that each child is considered in his/her singularity, and that produces symptoms (school failure, learning problems, exclusion). It is raised the hypothesis that the consideration of this (de)compass between languages may allow a harmony, even dissonant, and a provocation regarding the impossibility of obeying a commandment which goes against the desire.

KEY WORDS: Mother tongue, Foreign language, singularity, school routine, desire.

A relação entre língua materna e língua estrangeira inquieta e desperta a curiosidade dos professores de línguas estrangeiras. De modo geral, para mim, que trabalho numa instituição que se dedica ao ensino/estudo da tradução e da interpretaçáo, o contato com uma língua estrangeira é sempre o ponto que pré-ocupa essa passagem: deixar entrar ou barrar o estrangeiro? Como se dá ou se evita esse contato? É possível evitar a mistura? Há alguma forma de manter-se imune à interferência de uma língua na língua materna? De ser absolutamente fiel à língua do outro? O que fazer com os alunos que parecem teimar em não aprender? Por que alguns se tomam de amores e chegam a aprender mesmo por meio de métodos considerados "ultrapassados"?

A segunda parte do título deste trabalho - (Não) desejar as coisas alheias - foi escrita para ressoar como um mandamento posto entre parênteses, ligeiramente modificado, com o desejo no lugar da cobiça (mais ligada à inveja e ao olhar). Sabemos que todos os mandamentos são formas de proibição que "permitem", como diz Freud, que vivamos civilizadamente. Daí $O$ mal-estar na civilizaçáo, texto escrito no final de sua vida, em 1930, em que o inventor da psicanálise fala da necessidade de que o homem abdique do prazer individual e se desfaça de qualquer impulso que impeça a vida em sociedade. Todo corpo humano quer se satisfazer, gozar. Toda a questáo da educaçáo e do acompanhamento social visa justamente a submeter esse gozo ao social, isto é, à linguagem, ao simbólico, à lei. Todo sujeito está, portanto, preso entre a tensão de seu gozo e o imperativo da lei de viver entre outros; é isso que se chama propriamente de criação de sujeito - com todo o equívoco que a expressão acarreta -, um modo de se fazer nascer em suas obras. 
O alheio é também o outro, outro modo de dizer o estranho, e aparece no alienígena, no alienado, nas diversas formas de alteridade. Quanto ao X da questão, foi deixado lá mesmo onde o encontrei: no EX que comparece em "extranho", "extrangeiro", extraordinário - o ex é o que está

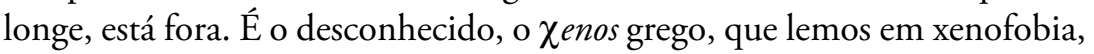
mas com um sopro de vida dessa língua, na qual o $\chi$ enos é o hóspede que, uma vez recebido na casa, passa a ser parte dela. Esses mesmos gregos que chamavam de bárbaras (como referência aos que falavam bar-bar-bar, isto é, não falavam grego) as línguas das quais só conseguiam captar o barulho, uma seqüência sonora que não conseguiam recortar em elementos significativos.Foi pensando nessa questão do estrangeiro estranho - trabalhada por Freud em 1919 ( $O$ estranho) - que lembrei de um velho conto, lido há muito tempo, mas de que só há pouco tempo pude perceber a sutileza lingüística, além de metodológica, de Edgar Allan Poe. Falo do conto: Os crimes da Rua Morgue, publicado em 1841. A epígrafe do conto é de Thomas Browne - médico, filósofo, religioso, esotérico, do século XVII, traduzido e amado por Borges (outro encenador das coisas estranhas), que diz que as Urnas sepulcrais de Browne eram verdadeiros pretextos para parágrafos musicais, que sugerem mais do que dizem. A epígrafe diz o seguinte: "Que canção cantavam as sereias? Que nome tomara Aquiles quando se ocultou entre as mulheres? Perguntas são estas de embaraçosa resposta, é certo, mas que não estão fora de possíveis conjeturas".

Estranha epígrafe para uma história de detetive, não fosse Edgar Allan Poe o autor. A voz das sereias que cantam na Odisséia atrai os marinheiros, captura-os, e Ulisses permite amarrar-se no mastro para ouvi-las sem ceder a seus encantos. A voz vai entrando pouco a pouco no conto, a começar pela do narrador. Anunciando um prefácio do conto, ele defende a capacidade de observação de detalhes, de levar em conta o que parece não ter importância, as "pequenas diferenças" (Freud, 1930), que estão na base do eu e do outro, resguardando suas fronteiras. O narrador conta entấo como conhecera o detetive francês Auguste Dupin, com o qual havia passado a residir. Elogia sua capacidade de análise e comenta o que chama de suas esquisitices e extravagâncias. Num final de dia, enquanto passeiam, lêem num jornal uma notícia: "Crimes extraordinários".

Num apartamento, quarto andar, da rua Morgue, mãe e filha são assassinadas de modo brutal. Os vizinhos ouviram gritos, mas demoraram para 


\section{Revista Solta a Voz, v. 19, n. 1}

acudir porque o apartamento estava todo fechado por dentro e tiveram de arrombar. Dentro, tudo na mais completa desordem, uma navalha manchada de sangue, tufos de cabelos [...] o cadáver da filha havia sido enfiado na chaminé da lareira e o da mãe estava em um pátio ao lado, com a garganta cortada.

O jornal do dia seguinte traz diversos depoimentos relatados no conto. Interessam-nos aqueles das pessoas que foram atraídas pelos gritos e vozes. Cito trechos adaptados dos depoimentos:

Isidoro Muset, policial. Ouviu duas vozes, uma delas rouca, a outra mais aguda, bastante estranha, aliás. Conseguiu distinguir algumas palavras da primeira, que seria de um francês: sacré e diable. A voz aguda, diz que era de um estrangeiro. Não entendeu o que dizia, mas acha que estava falando espanhol.

Henrique Duval, ourives. A voz aguda, segundo essa testemunha, era de um italiano. Com certeza não era de um francês. Podia ser de mulher. Não conhece a língua italiana. Não pôde distinguir as palavras, mas está convencido, pela entonação, de que era um italiano quem falava.

Odenheimer, dono de um restaurante. É natural de Amsterdã e, como não fala francês, foi interrogado por meio de um intérprete. Ouvira a voz grossa repetir diversas vezes: sacré, diable. Da voz mais áspera, não distinguiu as palavras pronunciadas e descreveu-as como rápidas e desiguais, parecendo exprimir medo e cólera.

Guilherme Bird, alfaiate, inglês. Ouviu as vozes que discutiam. A voz grossa era de um francês. Pôde perceber algumas palavras como sacré e Mon Dieu. A voz aguda era forte, mais alta que a voz grossa. Tem certeza de que não era voz de inglês. Parecia ser de alemão. Não compreende o alemáo.

Afonso Garcio, agente de funerais, natural da Espanha. Ouviu as vozes que altercavam. A voz grossa era de um francês. Náo pôde distinguir o que se dizia. A voz aguda era de um inglês, tem certeza disto. Não compreende a língua inglesa, mas julga pela entonação.

Alberto Montani, confeiteiro. Depóe que se achava entre os primeiros que subiram as escadas. Ouviu a voz grossa de um francês. Percebeu palavras. Não entendeu as palavras pronunciadas pela voz aguda, rápida e irregular. Acha que era uma voz de russo. Mas é italiano e nunca conversou com um russo. 
Todas as testemunhas concordam quanto à voz descrita como grossa, e nela conseguem distinguir palavras do francês. Quanto à outra, o especial não é terem discordado, mas atribuído essa voz ora a um italiano, ora a um inglês, um espanhol, um holandês e um francês; enfim, a alguém que era estrangeiro para cada um deles. Cada um compara a voz com a de um indivíduo que fala uma língua desconhecida, mas estranha, uma vez que as testemunhas, representantes de cinco potências européias, não reconheceram nada que lhes fosse familiar, embora ninguém duvide de que se trata de uma língua, uma vez que supóem que alguém a falava.

Dupin articula os depoimentos das testemunhas com as marcas deixadas no local do crime, que denunciam alguém capaz de uma agilidade espantosa, possuidor de uma força sobre-humana, de uma verdadeira ferocidade e questiona-se sobre a relação entre tal carnificina (para ele injustificável), algo grotesco e mesmo "extra-humano", e "uma voz de tom estranho aos ouvidos de homens de muitas naçóes e privada de qualquer enunciação distinta e inteligível”. O narrador argumenta que poderiam ser vozes de loucos, mas estes, mesmo em seus mais ferozes paroxismos, nunca se enquadram com aquela voz característica ouvida nas escadas. Os loucos pertencem, é claro, a alguma nação, têm sua língua, e, embora incoerentes nas suas articulaçóes, têm sempre a coerência da pronúncia das palavras.

Volto agora à relação singular entre língua materna e língua estrangeira: relação que permanece, de certa forma, ignorada em situação escolar.

Se pararmos por um instante para pensar seja na voz das sereias, seja na voz do gorila de Dupin (o duplo homicídio havia sido cometido por um gorila que havia escapado do cativeiro), uma coisa é certa: quando ouvimos uma língua desconhecida materializamos um corpo que fala. $\mathrm{O}$ corpo se faz presente porque não temos como recortar as seqüências sonoras que ouvimos. Ergue-se uma barreira, a mesma que o personagem de Chico Buarque, o ghost-writer José Costa, encontra na língua húngara, quando comenta o efeito produzido nele, um poliglota, pela seqüência de sons em que não consegue distinguir nada, a não ser no momento em que o locutor da TV diz a palavra Lufthansa, e ele comenta que ali estava enfim um buraquinho para entrar naquela língua... Que se observe, no 


\section{Revista Solta a Voz, v. 19, n. 1}

entanto, que essa permissão é dada por uma língua estrangeira que ele fala: o alemão.

Quando não conhecemos a língua, reparamos nos gestos, nas formas tomadas pela boca, nas posiçóes da língua do falante; enfim, estamos desprovidos da máscara dos sentidos, assim como o aluno que começa a aprender e tem dificuldade em pôr sua língua entre os dentes, porque aquilo que precisa articular não é um fonema em sua língua - ou seja, não serve para distinguir segmentos que façam sentido. Isso vale também para a "nossa" língua, que também se torna estranha na boca de outros: no paulista do interior que enrola o $/ \mathrm{r} /$, no carioca que produz fricativas "chiadas", no nordestino que abre as vogais... Tudo o que nos causa estranheza vem do outro - o outro é que tem sotaque; e é também algo outro que fala em nós e que desconhecemos: quando deixamos escapar algo que "não queríamos dizer".

Jean-Claude Milner (1978), lingüista e psicanalista, define língua materna como aquilo de que justamente a lingüística não trata, porque excede gramáticas e teorias, e pertence ao eixo da poesia, dos lapsos, dos jogos de palavras. Essa língua pode ser qualquer língua que materne um falante, que faça dele sujeito. Essa língua primeira é aquela que vai ser recalcada pelas leis da língua que captura a criança em suas malhas. A língua impóe sua lei, e escapar dela só é possível de duas maneiras: tecendo-a de forma a burlar essas leis, formar novas palavras, fragmentá-las em lugares inesperados... o que pode ser reconhecido como arte; ou saindo dela de modo perturbador, desconcertante, não dizendo "coisa com coisa", e ser reconhecido, então, como louco. Quanto às peraltices infantis com a língua, tão cheias de graças e encantamentos, uma coisa é a criança que derruba sobre ela um pote de creme e diz que está "toda creminosa", e outra coisa é Manuel de Barros, o poeta, dizer que "o grilo feridava o silêncio", ficcionando, distorcendo as regras da língua, criando um novo mundo e fixando-o numa escrita literária.

Logo que o bebê nasce, é sobre seus ombros que pesa o mundo. A temperatura muda bruscamente, a distribuição automática da alimentação é interrompida, o oxigênio tem que ser buscado no meio aéreo, assim como todas as substâncias indispensáveis à sua vida. Em seguida, a carne 
que nasce começa a gritar. Até aí, nada que diferencie esse bebê humano do animal, não está aí o nascimento do ser humano.

O momento da criação é o grito, mas somente a partir do instante em que é tomado como um apelo. A máe que recolhe o grito faz uma aposta sem garantia nenhuma: a aposta de que esse ser que grita vai ser habitado por um sujeito de fala: trata-se de um vir-a-ser falante, e ela o acolhe assim: bem-vindo ao mundo dos seres falantes. O grito do bebê é transformado pela mãe em um apelo. Trata-se de uma criação extraordinária, e que tem seus efeitos. De saída, ela faz cair no desconhecido a parte animal desse corpo. Daí em diante, é do lugar da fala que ele continuará - em um processo permanente, até a sua morte - a se fazer nascer.

Não basta sair do ventre da mãe para ter nascido. É preciso um segundo nascimento que não termina nunca. Nas palavras do viajante das veredas do sertão, "o homem não está nunca terminado". A acolhida à criança tem também um outro efeito benéfico: restabelece o equilíbrio rompido pela expulsão do corpo materno - ele é banhado em água morna, alimentado, ninado... Enfim, alguém responde a suas necessidades elementares. E há uma voz que prima, plena de música, que introduz na criança o sopro criador de falantes, e a criança recebe de sua mãe essas vibrações harmônicas, cintilantes, mutantes, da fala - acordossom. Esse primeiro tempo vai tornar-se depois o tempo de todas as nostalgias que vão alimentar as fantasias infantis no adulto, assim como alimentaram e alimentam os grandes mitos da humanidade.

Esse momento zero da chegada do sujeito é marcado pelo esquecimento, recoberto, apagado pela entrada do sujeito na linguagem. Apresenta-se como uma falta, um nada que vai se reproduzir sem cessar. Algum tempo depois, o corpo do bebê é submetido a um novo desequilíbrio. Reproduz o grito, que, tendo sido reconhecido, já faz dele um sujeito que apela, que se dirige, que apostrofa o Outro encarnado pela mãe (um outro) para sobreviver. Essa personificação, conhecida como uma figura de linguagem, aparece modificada em outra figura, a prosopopéia, que faz do personificado um agente discursivo (de pros = na direçáo de, e $o p-=$ ver, formando prosôpon = personagem, máscara e poieîn = fazer, dar corpo). Ao mesmo tempo em que nesse apelo ao Outro se personifica o ausente, produz-se um enunciador e um destinatário.

$\mathrm{O}$ que quer a criança? Ela quer o mesmo, a para sempre buscada primeira satisfação. A mãe interpreta as manifestaçóes da criança na lin- 


\section{Revista Solta a Voz, v. 19, n. 1}

guagem, supondo ali um sujeito: Será que está com fome? Sede? Medo? Dor? Quer aconchego? É manha? Quando ela acode pela segunda vez ao apelo do bebê, passou-se um tempo, a resposta não é idêntica, os cuidados podem não vir na mesma ordem, nem no mesmo ritmo. As palavras também mudam: o tom, a música da voz... E depois aparece uma outra voz mais grave, além de outras vozes. Há algum engano nisso tudo... Há o surgimento do desconhecido - Freud diz que entre a satisfação buscada pela repetição do grito e a satisfação obtida há um vão que marca a criança, desde seu nascimento, com a incompletude, o nada, o vazio, a falta: a linguagem é um malogro permanente do objeto de prazer - ela produz a queda e a ausência do objeto de satisfação, da satisfação que nunca deixará de buscar, mas a que vai precisar renunciar, diz Freud em Totem e tabu (1913), para pertencer ao mundo civilizado.

Lacan (1975) diz que os pais modelam o sujeito na função do simbolismo pela forma como instilam no bebê um modo de falar que porta a marca de como os pais o aceitaram. Mesmo a criança não desejada, acolhida mais tarde, pode guardar a marca de que esse desejo não existia antes. Nessa mesma conferência, Lacan afirma que a linguagem não tem existência teórica, e intervém sempre sob a forma do que ele chama de lalação. Assim, a língua constitui de alguma forma algo como um patrimônio, e é segundo o modo como ela foi falada e também ouvida - para cada um em sua particularidade - que alguma coisa re-sairá em sonhos, em todo tipo de modos de dizer.

Se, como afirmam os psicanalistas Jean Bergès e Gabriel Balbo (2002), somos todos bilíngües, é porque falamos uma língua que tem nela (esquecida) uma outra, uma reserva, uma estrangeiridade, algo que nos é alheio, que foi recalcado nessa língua materna primeira, e que nos faz desejar. Temos a língua materna das lalaçóes, dos jogos infantis, dos balbucios, dos primeiros interditos, das primeiras incompreensóes, mas também a língua marcada pelos limites impostos a todos que nela com-vivem. De tudo o que dissemos até agora, algo pode ser destacado: o que escutamos quando escutamos uma língua? Quando falo português, quem pode me garantir que estou falando "palavras" dessa língua? Estou falando "palavras" para quem fala português, mas o que estaria falando para um estrangeiro?

Acho que tudo isso é de uma simplicidade muito grande, mas que nos toca, a partir do instante em que nos damos conta de que a vida do ser humano não pode avançar senáo pela via da in-satisfação [no latim satis- 
facère $=$ fazer muito; de satis = bastante (saciar, assaz)]. Isso pode ser um modo de dizer que a vida que vivemos jamais fará por nós o suficiente. Essa falta aparece na mitologia, na religião como pecado original... enfim, como diz a canção The impossible dream, de Joe Darion e Mitch Leigh, em versão de Chico Buarque e Ruy Guerra, que homenageia o Quixote - "alcançar o inacessível... é minha lei, é minha questão...” eis a falta que faz a essência de nossa humanidade.

Outro modo de explicar o funcionamento de uma rede simbólica da língua é o jogo de peças que podem ser movidas para formar figuras, mas no qual precisa faltar uma peça, para que se possa jogar... jogos de combinações e deslizamentos, deslocamentos de peças. Tem que haver uma casa vazia, e essa casa vazia, que permite o jogo, podemos, muito simplesmente, chamar de desejo - trata-se de um "objeto" que falta e que é causa de desejo (preenchimento), cuja realização encerraria o jogo. Cortado do objeto de seu desejo, separado do que causa seu desejo, essa falta toma para o ser humano a forma de objetos de substituição, diz Freud (1907), que acredita que é também o que acontece na criação artística.

A cultura, a educação, a civilização impóem o sacrifício dessa falta. A criança quer tudo! Criar - na linguagem, sob todas as suas formas, com as palavras, matérias, sons, cores, dar corpo a combinatórias de significantes. O que no homem não fala, e quer satisfação, é o infans - que morre quando a máe o faz sujeito, assujeitado à ordem da fala e da linguagem, ou à ordem do discurso - a partir de então ele é dividido. "Pare de ser infantil!" Dizemos à criança, quando ela quer continuar brincando com a língua, permanecer fora da lei. A força, o impulso que Freud chamou de pulsão só existe como força produtiva porque encontrou em seu caminho uma barreira - a cultura dos homens, feita de linguagem. Falo aqui em linguagem no sentido global - tudo no homem é linguagem; o que não é e está excluído é o infantil, o in-fans, o que não fala. Quando passa por essa barreira, barragem, transforma-se essa energia bruta em energia "domensticada" (traduzindo um neologismo de Lacan), e pode encontrar outras veredas de criação.

Outras veredas que Freud nomeia como formaçóes do inconsciente - os lapsos: você quer dizer uma palavra e é outra que vem; ou ainda os atos falhos, os verdadeiros atos do inconsciente; e uma maquininha extraordinária para reciclar os desejos inconscientes e oferecer a eles uma via de criação: os sonhos. Se a força é muito forte, temos a passagem ao ato - age-se 


\section{Revista Solta a Voz, v. 19, n. 1}

em vez de falar - as vias socialmente aceitas estando impedidas, pode haver um ultrapassamento das fronteiras e, finalmente, as criaçóes mais surpreendentes - aquelas em que o corpo se póe a falar, os sintomas que Freud denomina: neuroses, psicoses e perversóes. $\mathrm{O}$ fato de que fazem sofrer não impede que sejam criaçóes. O paradoxo é que, sofrendo, o corpo produz um apaziguamento da pulsão. Quando lemos as Memórias de Paul Schreber, psicótico célebre estudado por Freud (1911), o psicanalista nos dá uma indicaçáo clínica precisa: quando um psicótico começa a delirar não é o momento de interrompê-lo - é seu modo de tratar a pulsão - o delírio é para Freud uma forma de criação. O delírio, com efeito, é uma produção em que a pulsão encontra as vias da linguagem, na fala, na escrita, em todas as vias... e encontra as vias da sublimação, isto é, da socialização.

Quanto à língua estrangeira, tomada agora no sentido usual de segunda língua, é preciso levar em conta que sua aprendizagem exige mediaçôes pedagógicas e técnicas, e pode se esgotar em um uso estritamente instrumental (tradução, comunicação, leitura); mais ainda, se prevalece o ideal de controle que marca o cotidiano escolar e não permite que se considere cada criança em sua singularidade, levando em conta seu desejo. A hegemonia desse ideal psicopedagógico acaba por produzir - no dia-a-dia das salas de aula - sintomas como o fracasso escolar, problemas de aprendizagem, exclusáo escolar. Levantamos a hipótese de que a consideração desse (des)compasso entre as línguas pode permitir uma harmonia dissonante e uma provocação quanto à impossibilidade de obedecer a um mandamento que contraria o desejo, que é sempre do outro, porque desconhecido para cada um.

No trabalho de alguns estudiosos franceses preocupados com a aprendizagem de línguas estrangeiras encontro uma experiência de uma pesquisadora em sala de aula, que foi adaptada para o contexto deste trabalho. Trata-se de uma conversa entre alunos (A1, A2) franceses de 9 a 11 anos e sua professora (Prof.) com a finalidade de despertar seu interesse pelo estudo de outra língua, no caso, o alemão. Esse diálogo foi traduzido e adaptado do artigo de Lucette Colin (2005):

A1: Por que aprender uma língua? Por que falar uma língua?

A2: Mas o francês é uma língua.

A1: É, mas a gente aprende sozinho sem dicionário.

A2: Mas existem dicionários em francês, meu irmão tem um.

A1: É, mas a gente aprende sozinho, não precisa ir na escola... só pra ler e escrever. 
Prof.: Então um bebê nasce, fica sozinho, e fala francês?

A1: Se nasce na França... e se seus pais falam...

A2: E se nasce na França, mas os pais são alemães?

A1: Aí ele fala alemão. Os pais sáo o mais importante. Eles têm os mesmos cabelos, os olhos. Tenho os olhos do meu pai.

A2: Ah. Não acho. Se a pessoa não ouve, não fala.

Prof: O que você (A1) acha?

A1: É, ele tem razão. Tem que ter os pais falando e falando... [risos]. E tem mais. A gente fala para chamar, pedir coisas: mamãe, mamadeira, papar... é mais rápido para entender quando você mesmo fala.

Prof: Você sabe o que é língua materna?

A2: É o francês... e os pais querem que a gente fale francês para eles entenderem, senão a gente diz Scheisse e eles não entendem (risos).

A1: Ah! Eles compreendem sim... nós aprendemos rapidinho. Você diz e ri, e eles compreendem.

Uma criança alemã, continua Colin, conta que um colega francês havia lhe ensinado a dizer merde, e ela havia entendido outra coisa... Bem depois é que ela percebeu que merde queria dizer Scheiße em alemão, e só então ela riu de seu engano, porque antes ela tinha entendido mörder (assassino, em francês).

$\mathrm{Na}$ sua escuta, ela estava não no sistema clássico de tradução, mas em um sistema pessoal, marcado pelo afeto, cujo procedimento "científico" poderia ser o seguinte: ela entende algo dessa palavra (merde), não sua relação interlingüística com a palavra de sua língua Scheiße, mas o tom de algo agressivo. O que ela ouviu, ela associou a uma palavra de sua língua materna, de "sentido" semelhante ou com uma mesma ressonância afetiva para ela. Mas, acima de tudo, essa palavra tem também sons e fonemas comuns, o que lhe permite ouvir mais afetivamente. Para dizer de outro modo, uma palavra de sua língua materna permite-lhe verbalizar, como observa a pesquisadora, o que ela ouve do colega francês, e isso porque há elementos fonéticos comuns. Podemos supor que seu prazer não está ligado ao alívio de aprender o que é merde, mas de aprender que essa palavra náo era dirigida a ela (como parecia indicar mörder, assassino). O prazer diante do engano vem também de sua descoberta de que as palavras dizem um texto "outro", e não aquele em que ela acreditava. É o mesmo prazer que encontramos no chiste: o prazer se torna mais vivo quando se ri, se o engano joga em um outro registro. 


\section{Revista Solta a Voz, v. 19, n. 1}

A graça do jogo está em não se prender ao sentido, em náo tentar compreender (traduzir), mas em buscar associar tais palavras aos sons da língua materna. Gozando das palavras, a criança barra o estrangeiro delas, e apropria-se dela como de uma criação poética, faz sua a língua estrangeira, manipula essa língua estrangeira em harmonia com a língua esquecida das lalaçóes.

A relação de cada um com a língua estrangeira é particular, e a escola trabalha com a uniformidade: é sua garantia como tentativa para lidar com línguas minoritárias, para contrabalançar a imposição do lugar. Quanto aos alunos com problemas - dificuldade com a língua estrangeira na escola, mau aluno nas matérias em geral - é preciso levá-los a descobrir a relatividade de uma lei (na sala de aula, na língua, concepções de educação etc.).

As metodologias propostas ignoram forçosamente que no encontro entre alunos e professores esteja presente o inesperado, a indeterminação que já existe na etimologia da palavra educar, que vai do "incentivar", do "nutrir", ao "conduzir"; que se faça presente o inconsciente que insiste em distanciar o ideal e o real, e que não permite o encontro previsto, esperado.

Podemos observar que a necessidade pedagógica de abafar esse inesperado, esse inconsciente, é intrínseca à própria visada metodológica, em detrimento das mesmíssimas condições de possibilidade de uma educação. Ao procurar acabar com a ambigüidade da educação, promove-se a tentativa de supressáo de um real estranho e resistente às previsóes pedagógicas. Nenhuma metodologia de ensino de algum tipo $x$ ou $y$ pode ser capaz de apagar a singularidade da relaçáo primeira de uma criança com sua língua materna, nem a singularidade da relação que o professor estabelece com uma disciplina particular e com o seu ensino. A tentativa de construir uma nova metodologia que responda ao ideal de homogeneização deixa de lado os desejos singulares que vão constituir aquela maneira única de cada professor ensinar, em nome da urgência de criar um método único.

Este trabalho abre-se com uma série de questóes sobre a relação entre língua materna e língua estrangeira. Esse contato é abordado na escola, e terminamos por nos perguntar: o método teria uma capacidade mágica de homogeneizar as diferenças e singularidades do aprendiz? $\mathrm{O}$ modo de agir de certo professor pode ser apagado pela proposta unificadora de algum método? Existe um método que torne possível minimizar as dificuldades 
de aprendizagem das crianças? É possível acreditar ainda que o professor tem o poder de calcular os efeitos dos métodos que aplica?

Aos poucos, levando em conta algumas considerações da psicanálise sobre questóes educativas, descobrimos que a criança aprende muito mais com o Professor, por amar esse Professor, por transferir-lhe o poder de saber ensinar, do que com os métodos, por mais "animados" que possam parecer.

Foi Freud quem, deslocando o pensamento cartesiano e sublinhando o pensamento inconsciente, apontou o desamparo do ser humano e a força do desejo que o move. Entre o paciente em tratamento no consultório e as reflexóes sobre o mal-estar na civilização, Freud encontra, como não poderia deixar de ser, a educação e suas (im)posssibilidades. Deixo com ele a última palavra, em um momento no qual, refletindo sobre a sua vida de estudante e sobre a psicologia do escolar, afirma:

é difícil dizer se o que exerceu mais influência sobre nós e teve importância maior foi a nossa preocupação pelas ciências que nos eram ensinadas, ou pela personalidade de nossos mestres. É verdade, no mínimo, que esta segunda preocupação constituía uma corrente oculta e constante em todos nós e, para muitos, os caminhos das ciências passavam apenas através de nossos professores. Alguns se detiveram a meio caminho dessa estrada e para uns poucos - porque não admitir outros tantos? ela foi por causa disso definitivamente bloqueada. (Freud, 1914, p. 286)

Freud argumenta que transferimos para esses professores algo que se relacionava com as nossas vivências domésticas. Nossos mestres são muito mais do que construtores de técnicas, métodos e estratégias para uso em sala de aula. É importante ressaltar a relevância de nossos antigos mestres; e lembrar que transferimos "para eles o respeito e as expectativas ligadas ao pai onisciente de nossa infância e depois começamos a tratá-los como tratávamos nossos pais em casa” (idem, p. 286).

\section{REFERÊNCIAS}

BERGÈS, J. e BALBO, G. Jogo de posições da mãe e da criança: ensaio sobre o transitivismo. Tradução de N. Leite, V. Veras e A. Vorcaro. Porto Alegre: CMC, 2002. 


\section{Revista Solta a Voz, v. 19, n. 1}

COLIN, L. Les classes de nature Franco-Allemandes ou apprentissages internationaux et interculturels. Em: Rencontres d'enfants de 9 à 11 ans, élèves allemands et français. Disponível em http://www.ofaj.org/paed/arbeitstexte.html. Acesso em março de 2005.

FREUD, S. Escritores criativos e devaneios (1907). In: Obras Psicológicas Completas de Sigmund Freud. v. IX. Rio de Janeiro: Imago, 1996.

. Notas psicanalíticas sobre um relato autobiográfico de um caso de paranóia (dementia paranoides) (1911). In: Obras Psicológicas Completas de Sigmund Freud. v. XII. Rio de Janeiro: Imago, 1996.

. Totem e tabu (1913). In: Obras Psicológicas Completas de Sigmund Freud. v. XIII. Rio de Janeiro: Imago, 1996.

. Algumas reflexóes sobre a psicologia do escolar (1914). In: Obras Psicológicas Completas de Sigmund Freud. v. XIII. Rio de Janeiro: Imago, 1996.

. O estranho (1919). In: Obras Psicológicas Completas de Sigmund Freud. v. XVII. Rio de Janeiro: Imago, 1996.

. O mal-estar na civilização (1929). In: Obras Psicológicas Completas de Sigmund Freud. v. XXI. Rio de Janeiro: Imago, 1996.

LACAN, J. Conférence à Geneve sur le symptome (1975). In: Le Blocnotes de la psychanalyse, n. 5, Genf, 1985.

MILNER, J-C. L'amour de la langue. Paris: Seuil, 1978.

POE, E. A. Ficção completa, poesia e ensaio. Tradução e organização de Oscar Mendes. Rio de Janeiro: Nova Aguilar, 1981.

Recebido em: 10 abr. 2008 Aceito: 10 jun. 2008 